\title{
The Conservation and Development of Isan Long-Drum Performances to Promote Local Culture
}

\author{
Yutthasilp Chuthawichit ${ }^{1}$, Boonsom Yodmalee $^{1} \&$ Suwimon Poklin $^{2}$ \\ ${ }^{1}$ Faculty of Cultural Science, Mahasarakham University, Muang District, Maha Sarakham Province, Thailand \\ ${ }^{2}$ Faculty of Education, Ubon Ratchatani Rajabhat University, Ubon Ratchatani Province, Thailand \\ Correspondence: Yutthasilp Chuthawichit, Faculty of Cultural Science, Mahasarakham University, Muang \\ District, Maha Sarakham 44000, Thailand. Email: Yut1957@yahoo.co.th
}

Received: April 23, 2014 Accepted: June 6, 2014 Online Published: June 12, 2014

doi:10.5539/ach.v6n2p191 URL: http://dx.doi.org/10.5539/ach.v6n2p191

\begin{abstract}
Problem Statement: An Isan long-drum performance is a tradition inherited from ancestors and has an important role in Thai society. Due to outside influence, the tradition has been changed; people failed to keep their ethnic and cultural identity. Despite some development of concepts, a lack of understanding in the art decreased the value of performances to a large extent. The objectives of the study were to examine the historical background and composition of Isan long-drum performances; the current circumstances and problems of Isan long-drum performances; and conservation and development model of Isan long-drum performances to promote local culture. Approach: The study was conducted during August, 2009 to October, 2011 and in four provinces: Maha Sarakham, Roi Et, Yasothon, and Ubon Ratchatani. Twelve drum bands were chosen purposively for the study, three for each Province. There were 162 samples. The research tools used were a basic survey observations, and interviews. The analysis was done descriptively. The results were as follows:

The research found that the historical background and compositions of Isan long drum performances were related to drum performances in Myanmar and Laos. The music and its compositions in the given countries were similar. In Thailand, drum performances were and still are performed in the North, Central, and Isan or Northeast. In the past, such performances were done only during religious ceremonies. However, it was not clearly know where the performances were originated. It was clear that they were passed down from previous generations.

Upon current circumstances and problems of drum performances in Isan, the study found that the bordies of the long-drum were made of jackfruit or Samanea saman (Cham Churi trees) wood because of its light weight and the good sound they made. Unfortunately, the given trees were decreased because of home furniture market. The long drum groups had time for rehearsals after dinners. There were attempts to keep long drum traditional rhythms and songs. For maintaining Isan long-drum performances, support funding was needed.

For development of Isan long-drum performances to promote local culture and drums, each of the four long drum groups had more drums than they did in the past, such as an electric organ, bass, and three-drum sets. The music and songs played were traditional Thai music with faster rhythms, folk songs, and country music.
\end{abstract}

Keywords: conservation, revitalization, development, long-drum performance, cultural promotion

\section{Introduction}

Isan communities were flourished before. People had traditions, beliefs, and way of life especially the annual or twelve year-round traditions. Such morally persuaded people live and work together. A way of support themselves while working is entertainment. They made music instruments for that purpose. Some of them were Polang, Khaen, Pin (Guitar), Wode, and drums. Drums were used in many occasions in the past and so are today. They are used in rituals as well as giving signals or reflecting events within community (Bulalee, 1994). Drums are also used for giving rhythms, playing with other music instruments, calling meetings or preparing to go to war.

There are many kinds of drums in Isan. Each has its own functions (Varangrat, 1986). Drums mostly used in performances in Central Isan were long drums. They were used in the processions of ht 12-month traditional festivals. Long drums were used during the first lunar month for house opening and New Year celebration. During the $2^{\text {nd }}, 3^{\text {rd }}$, and $4^{\text {th }}$ lunar months, long drums were for cloth offering (Bun Papa) and Phawet festival (to 
celebrate the return to the palace of Wetsandon). During the $5^{\text {th }}, 6^{\text {th }}$, and $7^{\text {th }}$ and $11^{\text {th }}$ lunar months, the long-drum performances were carried out for cloth offerings, Songkran and Rocket festivals, Buddhist ordination, and Bun Kathina (Sodsuchart, 1983)

Isan people are mostly Buddhists. For them, Buddhism was and still is believed to be the center of people's mind bringing love, social unity and art and at the same time contributing belief, rituals, and traditions to society.

There had been development of sound system especially the musical components, materials, and methods. The chords, rhythms, styles of dancing, dresses, and other integrated activities were created by artists making new looks of Isan long-drum performances. Currently, some long-drum performing groups could make some earnings. Most of the group members considered the extra earnings to be very important for them.

Most on-lookers and those were interested in long-drum performances came up with an idea of long-drum performances came up with an idea of long-drum contests. Such was done lightly and had little effect on the people and many long-drum performers gave up their performance. Moreover, some outside influences, such as movies, dramas, and karaoke luring people or the public to new types of entertainment. It was difficult for each long-drum performing group to stay in business. Fewer performances meant less income earnings.

- Some main problems of the long-drum performers came from three parts: the sound quality of the long-drums; the management of the long-drum performing groups; and the long-drum competition.

- Of the sound quality of the long-drums, the problems arose from the quality of maintaining the leather used as the covers of the long-drums. The leather needed a good maintenance regularly using human saliva. Both were mixed together and pasted over the covers of long-drums. Whether they performed or not, good maintenance of drum-covers should be done on a regular basis. If not, fine sound quality was hard to get. As a result, each long-drum performing group needed to have some one taking a good care of the drum covers.

- The selection and training of members of each long-drum performing group. Long-drum players were around in their village and the villages nearby, but there were not the good ones to be selected from. To get some good ones needed inspiration, support, and training. Each long-drum group leader needed to have some financial support for training and music teachers. Dancers also needed some training. Each group was supposed to hire good teachers of classical and applied dances.

- Although winning long-drum competition was inspired by most long-drum players as well as the long-drum performing groups. Yet winning a long-drum competition needed a lot of patience, training experiences, and financial support. Lacking one or two of these could affect the long-drum performing to achieve or win good prizes. Achieving good winning prizes meant popularity and more chances of getting performing jobs. To stay in business, each performing group had to have some money to go around and needed more rehearsals. Some group members needed to look for jobs elsewhere and could not participate the long-drum performing group regularly. Some gave important, therefore, to conduct research on conservation, revitalization, and development of Isan long-drum performances to promote local culture.

\section{Objectives}

- To study the historical background and composition of Isan long-drum performances.

- To study current circumstances and problems of Isan long-drum performances.

- To study models for conservation, revitalization, and development of Isan long-drum performances to promote local culture.

\section{Methodology}

\subsection{The Study Areas and Respondents}

This qualitative research was based on documentary studies and field work. The researcher spent months reviewing related documents and research literature. The field work was carried out in four Provinces in Northeastern Thailand: Maha Sarakham, Roi Et, Yasothon, and Ubon Ratchatani. The 162 sample, chosen purposively, included $12 \mathrm{key}, 60$ casual, and 90 general respondents respectively.

\subsection{Research Tools and Data Collection}

The research tools used for data collection besides documentary studies were a basic survey, observations, interviews, focus-group discussions, and workshops. The field work was carried out between October, 2011 and March, 2012. 


\subsection{Data Analysis}

The research data were analyzed descriptively based on the research objectives and a triangulation technique. Cultural and social theories were appropriately used to verify the research results.

\section{Results}

Based on the research objectives, the results found were as follows:

Upon the historical background and composition of Isan-long drum performances, the study found that the tradition of long-drum performances had cultural ties with neighboring countries, such as Myanmar and Laos. The three countries shared similar religious beliefs, traditions, and music. In Northern Thailand, the long-drum performances were carried out in temple to worship sacred shrines. For the Central and Northeastern Thailand, the tradition of long-drum performances was done only in Buddhist rituals, such as ordination, Kathina, and Papa processions. However, it was not clear when such a tradition began in the Northeastern Thailand. The front part or the beating side with 7-12 inches wide was covered with leather. The music composition of Isan long-drum performances included 3-5 drums: a big drum (Klong Tung or Tam bourine), one or two pairs of cymbals, castanets, Krap Gap. Five to ten long-drums could be added. The styles of dances varied and the audience could also join in dancing. Members of each long-drum performing group wore their own uniforms. Various government offices supported long-drum competition in 1973 and from then on long-drum performing groups were formed and dancing styles and clothes were designed.

Upon the current circumstances and problems of Isan long-drum performances, the study found that long-drum makers had diffulties getting the right materials (jackfruit wood) for drum making. Jackfruit wood has the right texture and light-weight and can affect the quality of sound. The wood second best for long-drum making is Cham Churi. However, such wood becomes scare due to its use in furniture manufacturing. Most long-drum makers used both simple and hard tools. Only at Ban Khumdin, the long-drum makers used a grinding machine. Although members of long-drum makers were farmers, they could find time to rehearse in the evening and before the end of each Buddhist Lent. A month-long after that was the Kathina season during which there were a lot of parades or long-drum performances waiting for them. Currently, traditional drum rhythms and music had been changed due to value of the hiring hosts and lack of conservation of rhythms and music. There had been attempts to develop dancing styles and gestures accompanying the long-drum performances. Basically, the long-drum performers themselves knew how to improve their performances. The capital used in the management of long-drum performing groups came from the groups' own savings and donation from local and national politicians, general public, Buddhist monks, and government officers. The money was used to support performers or repair of music instruments.

As for model for conservation, revitalization, and development of long-drum performances to promote local culture, the study suggested guidelines for conservation, revitalization, and development of Isan long-drum performance which included long-drums, melodies, and tambourines. Each long-drum performing group bought new long-drums and tambourines. Signs of Isan long-drum development included funds, popularity, and physical development of long-drums and tambourines. For acceptable long-drum performances, each long-drum performing group needed good quality leather, wooden-long drum bodies and other instruments, such as castanets, cymbols, an electric organ, three solo drums, and a bass. The electric organ was used as a musical controller.

\section{Discussion}

The discussion focused on 3 aspects: historical relations, current circumstances and problems, and models for conservation, revitalization, and development of Isan long-drum performances.

On the historical relations of Isan long-drums, the study found that Isan long-drums evolved all along with art and religious belief. Throughout history of Isan, long-drums were used in Buddhist religious rites all year-round called Heed Sibsong. The tradition as such was, and still is, a combination of Buddhist, Brahmanis, and animistic beliefs, Having faith in what they believed, they built fine quality artistic cultural materials, such as long-drums (Pinichpon, 2010) that the first long-drum performing group was established in Wapi Pathum District, Maha Sarakham Province in 1981. The name of the group was Song Jan. Later it was changed to Dao Luke Kai and the group made their own long-drums. Since then, Wapi Pathum District has been known for long-drum performances. The compositions of each long-drum group performance included long-drums, tambourines, castanets, cymbals, and 14 long-drum rhythm slashes. Isan long-drum performances have been widely used in local and traditional processions, such as Bang Fai, Candle, and Noodle festivals, and Buddhist ordination. All drummers wore local styled sarong and short-sleeve blue shirts with one loincloth tying around waist and 
another one around their head.

Long-drum performances changed due to social and cultural value brought from outside, such as rhythms, dresses, and dancing styles. Such a finding was in agreement with Ranjuan Isranouwat (1999) that the long-drum performances in Sri Somdej District, Roi Et Province, evolved from traditional to applied ones having music and dances accompanying the processions. The melodies played were Thai country and folk songs. Such was in consistent with Nopparat Buapat (1999) thay long-drum performances were for entertainment-7 out of 12 months annually (the $3^{\text {rd }}, 4^{\text {th }}, 5^{\text {th }}, 6^{\text {th }}, 8^{\text {th }}, 11^{\text {th }}$, and $12^{\text {th }}$ ). For other month, the people carried out religious activities and did not need long-drum performances. Nevertheless, such performances served both religious beliefs and social entertainment and needed development model, rhythms, accompanied songs or music, dresses and dancing styles. More importantly, the way the long-drum performances were carried out reflected integrated local wisdom and artistic aesthetics. Such was in agreement with Sanya Sanyawiwat (1988) that human society according to Durkheim's Functional theory, was an entity and had an organism; each part of society had a role to play to satisfy the needs of its members.

The current circumstances and problems of Isan long-drum performances were related to social and economic changes. As more and more family members sought employment in town or city areas, their taste of music and entertainment also changed. Folk music, such as long-drum performances, therefore, applicably used electric music instruments. Such was in agreement with Sombat Tabthimthong (2001) that groups of long-drum performances in Wapi Pathum District, Maha Sarakham Province were forced to change, such as dresses, performing styles, and using modern music instruments, such as electric organ, bases, solo drums. Government and private sectors provided financial support. Such was in agreement with Supawan Ubonlert (2007) that long-drum performances continually changed their dancing styles, contents, music instruments to meet the needs of audience and their ethnic background.

Upon the model for conservation, revitalization, and development of Isan long-drum performances to promote local culture, the Ministry of Culture stepped forward asking concerned officers and schools of all levels to establish own syllabus utilizing local wisdom. Qualified teachers, folk musicians and performers were able to continuously train interested citizens to perform their best performances. The long-drum performing groups in Wapi Pathum District, Maha Sarakham Province successfully developed their performances and adopted whatever they saw necessary, such as using solo drums, electric organs, guitars, and saxophones and integrating cultural value, attitude, ideology, and knowledge. To stand firmly together, the groups needed understand and cooperation among group members. Money making was not their goal, but conserving and developing the long-drum performances was. They all worked hard to achieve such a goal. They were proud of their achievement. Moreover, they had set a good example to the public that long-drum performances could be conserved, revitalized, and developed to very great extent.

\section{References}

Sodsuchart, B. (1983). Bang Fai: Royal Project for Book Promotion. Bangkok: Sak Sopa Printing.

Bulalee, N. (1994). Klong Seng. Roi Et: Roi Et College of Dramatic Arts.

Buapat, N. (1999). Klong Yao and Heed Sibsong Tradition, Ban Yang Ku, Thawat Buri, Roi Et Province. Maha Sarakham: Mahasarakham University.

Isranouwat, R. (1999). Klong Yao of Sri Somdej People, Roi Et Province. Maha Sarakham: Mahasarakham University.

Sanyawiwat, S. (1988). Theory and Strategic for Social Development. Bangkok: Chulalongkorn University.

Tabthimthong, S. (2001). Conditions of Existence of Wapi Pathum Klong Yao Groups, Maha Sarakham Province. Maha Sarakham : Mahasarakham University.

Ubonlert, S. (2007). A Development Model of Music Culture and Isan Folk Performances of Roi Et College of Dramatic Arts. Maha Sarakham: Mahasarakham University.

Varangrat, S. (1986). A Cultural Comparative Study of Phuthai and So. Sakon Nakhon: Facultyof Humanities and Social Sciences, Sakon Nakhon Teachers' College.

Pinichpone, S. (2010). A Guideline for and Application of Klong Yao (Long-Drum) for Community Health Promotion, Maha Sarakham Province. Maha Sarakham: Mahasarakham University. 


\section{Copyrights}

Copyright for this article is retained by the author(s), with first publication rights granted to the journal.

This is an open-access article distributed under the terms and conditions of the Creative Commons Attribution license (http://creativecommons.org/licenses/by/3.0/). 